\title{
Structural phase evolution of strontium-doped lead titanate thin films prepared by the soft chemical technique
}

\author{
F.M. Pontes \\ Laboratório Interdisciplinar de Eletroquímica e Cerâmica (LIEC), Centro Multidisciplinar Para \\ Desenvolvimento de Materiais Cerâmicos (CMDMC), Departamento de Química, Universidade \\ Federal de São Carlos (UFSCar), Via Washington, Km 235, CP-676, CEP-13565-905, \\ São Carlos, S. P., Brazil \\ S.H. Leal \\ Laboratório Interdisciplinar de Eletroquímica e Cerâmica (LIEC), Centro Multidisciplinar Para \\ Desenvolvimento de Materiais Cerâmicos (CMDMC), Departamento de Química, Universidade \\ Federal de São Carlos (UFSCar), Via Washington, Km 235, CP-676, CEP-13565-905, São Carlos, \\ S. P., Brazil, and Centro de Ciências da Natureza (CCN), Departamento de Química, Universidade \\ Federal do Piauí (UFPI), Teresina, PI, Brazil \\ P.S. Pizani \\ Departamento de Física, Universidade Federal de São Carlos (UFSCar), Via Washington, Km 235, \\ CEP-13565-905, São Carlos, S. P., Brazil \\ M.R.M.C. Santos \\ Centro de Ciências da Natureza (CCN), Departamento de Química, Universidade Federal do Piauí \\ (UFPI), Teresina, PI, Brazil \\ E.R. Leite ${ }^{\text {a) }}$ and E. Longo ${ }^{\text {) }}$ \\ Laboratório Interdisciplinar de Eletroquímica e Cerâmica (LIEC), Centro Multidisciplinar Para \\ Desenvolvimento de Materiais Cerâmicos (CMDMC), Departamento de Química, Universidade \\ Federal de São Carlos (UFSCar), Via Washington, Km 235, CP-676, CEP-13565-905, \\ São Carlos, S. P., Brazil \\ F. Lanciotti, Jr. and T.M. Boschi \\ Departamento de Física, Universidade Federal de São Carlos (UFSCar), Via Washington, Km 235, \\ CEP-13565-905, São Carlos, S. P., Brazil \\ J.A. Varela \\ Instituto de Química, Universidade Estadual Paulista (UNESP), Araraquara, S. P., Brazil
}

(Received 27 July 2002; accepted 13 December 2002)

Strontium-modified lead titanate thin films with composition $\mathrm{Pb}_{1-x} \mathrm{Sr}_{x} \mathrm{TiO}_{3}$ were grown on $\mathrm{Pt} / \mathrm{Ti} / \mathrm{SiO}_{2} / \mathrm{Si}$ substrates using the polymeric precursor method. The structural phase evolution as a function of the Sr contents was studied using micro-Raman scattering, specular reflectance infrared Fourier transform spectroscopy, and x-ray diffraction. The results showed a gradual change from tetragonal to cubic structure, the transition occurring at about $x=0.58$. The infrared reflectance spectra showed that the frequency of several peaks decreases as the strontium concentration increases. These features are correlated with a decrease in the tetragonal distortion of the $\mathrm{TiO}_{6}$ octahedra as the strontium concentration increases.

\section{INTRODUCTION}

Intensive research has been focused on ferroelectrics thin films in the last decade with particular emphasis on new processing and characterization techniques. ${ }^{1,2} \mathrm{~A}$ considerable amount of research has been developed for

a)e-mail: derl@power.ufscar.br

b) Address all correspondence to this author.

e-mail: liec@power.ufscar.br thin films because of their potential applications in the field of microelectronic and optoelectronic devices. ${ }^{3,4}$ Among the ferroelectric thin films, $\mathrm{PbTiO}_{3}$ has received special attention in recent years due to its applications such as pyroelectric infrared detectors, piezoelectric sensors, optical switches, and dynamic random-access memory (DRAM) and nonvolatile ferroelectric randomaccess memory (NVFRAM) devices. ${ }^{5-7}$ On the other hand, pure $\mathrm{PbTiO}_{3}$ has a large tetragonal distortion at room temperature, approximately 1.064 , which introduces 
a stress upon the cooling through the phase transition, producing cracking in the material. ${ }^{8}$ Recently, $\mathrm{Ca}-$, La-, or $\mathrm{Sm}$-doped $\mathrm{PbTiO}_{3}$ thin films have been focused toward establishing the structure-property relationships to modify their optical, structural, and electrical properties. ${ }^{9-11} \mathrm{Ca}$ substitution reduces the tetragonality (approximately), reducing the strain of pure $\mathrm{PbTiO}_{3}$ thin films, and inhibits cracking. Wang et al. ${ }^{12}$ showed that sol-gel-deposited $(\mathrm{Pb}, \mathrm{Ca}) \mathrm{TiO}_{3}$ (PCT) films exhibited a low tetragonal distortion and hindered the grain growth in the microstructure, both by means of the increase of the $\mathrm{Ca}$ content. La-doped $\mathrm{PbTiO}_{3}$ thin films show very good pyroelectric properties, and the approximate ratio decreases with increasing La concentration. ${ }^{13}$ However, there is only little work on $(\mathrm{Pb}, \mathrm{Sr}) \mathrm{TiO}_{3}$ thin films. It is well know that $\mathrm{PbTiO}_{3}$ and $\mathrm{SrTiO}_{3}$ are very typical perovskite materials and they can form solid solutions in a wide range of compositions. Chung et al. ${ }^{14}$ reported PST $(\mathrm{Pb}, \mathrm{Sr}) \mathrm{TiO}_{3}$ thin films prepared by liquid source misted chemical deposition, where the leakage current density was greatly influenced by the postannealing in $\mathrm{O}_{2}$ and $\mathrm{N}_{2}$ ambient gas. Recently, Kang et al. ${ }^{15}$ reported $(\mathrm{Pb}, \mathrm{Sr}) \mathrm{TiO}_{3}$ thin films prepared by the sol-gel process and their characteristics were investigated as a function of the strontium content. However, in both works detailed studies using spectroscopy techniques were not accomplished. Furthermore, micro-Raman and infrared (IR) spectroscopy have, over the years, emerged as rapid and very sensitive techniques for comprehensive material characterization in thin films. The micro-Raman and IR techniques can also be used to study the effects of the size and stress on the actions of the phonon modes, contributing to the understanding of physical properties in the ferroelectric phase.

Reports on Raman spectroscopy study of perovskite $(\mathrm{Pb}, \mathrm{Sr}) \mathrm{TiO}_{3}$ thin films prepared by soft chemical processing are difficult to find in the literature. Hence, in this paper, we report experimental data to reveal the effects of the Sr contents of the soft chemically prepared $(\mathrm{Pb}, \mathrm{Sr}) \mathrm{TiO}_{3}$ thin films on the vibrational properties using Raman and Fourier transform infrared (FTIR) spectroscopies to provide the detailed information on molecular and group vibrations in the surface layers.

\section{EXPERIMENTAL}

$\mathrm{Pb}_{1-x} \mathrm{Sr}_{x} \mathrm{TiO}_{3}$ (PST) thin films studied in this work were derived from a soft chemical processing with $\mathrm{Sr}$ contents corresponding to $x=0.10,0.20,0.30,0.40$, and 0.50 . Details of the preparation method can be found in the literature. ${ }^{16,17}$ The polymeric precursor solution was spin-coated on substrates $\left[\mathrm{Pt}(140 \mathrm{~nm}) / \mathrm{Ti}(10 \mathrm{~nm}) / \mathrm{SiO}_{2}\right.$ $(1000 \mathrm{~nm}) / \mathrm{Si}$ ] by a commercial spinner operating at $6000 \mathrm{rev} / \mathrm{min}$ for $20 \mathrm{~s}$ (spin-coater KW-4B, Chemat Technology, Northridge, CA), via a syringe filter to avoid particulate contamination. After spinning, the films were kept in ambient air at $150{ }^{\circ} \mathrm{C}$ on a hot plate for $20 \mathrm{~min}$ to remove residual solvents. A two-stage heat treatment was carried out with initial heating at $400{ }^{\circ} \mathrm{C}$ for $4 \mathrm{~h}$ at a heating rate of $1{ }^{\circ} \mathrm{C} / \mathrm{min}$ in an oxygen atmosphere for the oxidation of residual organics, finally followed by heating at $600{ }^{\circ} \mathrm{C}$ for $2 \mathrm{~h}$ for crystallization. The film thickness was controlled by adjusting the number of coatings and the coating/drying operation repeated until the desired thickness was obtained.

The micro-Raman measurements were performed at room temperature as a function of the $\mathrm{Sr}$ content, using the 514.5-nm line of an argon ion laser as the excitation source. The power was kept at $15 \mathrm{~mW}$, and a $100 \times$ lens was used. The spectra were recorded using a T-64 JobinYvon (Longjumeau, France) triple-monochromator coupled to a charge-coupled device detector. IR analyses were performed by using an Equinox/55 (Bruker, Billerica, MA) FTIR spectrometer to observe the variations in the chemical bond densities. The FTIR reflectance spectra of the thin films were recorded at room temperature in the frequency range $350-1200 \mathrm{~cm}^{-1}$ equipped with a $30^{\circ}$ specular reflectance accessory.

To corroborate the interpretations, $(\mathrm{Pb}, \mathrm{Sr}) \mathrm{TiO}_{3}$ thin films were also structurally characterized by $\mathrm{x}$-ray diffraction (XRD) $\left(\mathrm{Cu} \mathrm{K} \mathrm{K}_{\alpha}\right.$ radiation) in the mode of $\theta-2 \theta$ scan, recorded on a Rigaku diffractometer (D/ $\max -2400)$.

\section{RESULTS}

The room-temperature micro-Raman spectra of PST thin films for the different compositions are displayed in Fig. 1, within the frequency range from 30 to $850 \mathrm{~cm}^{-1}$.

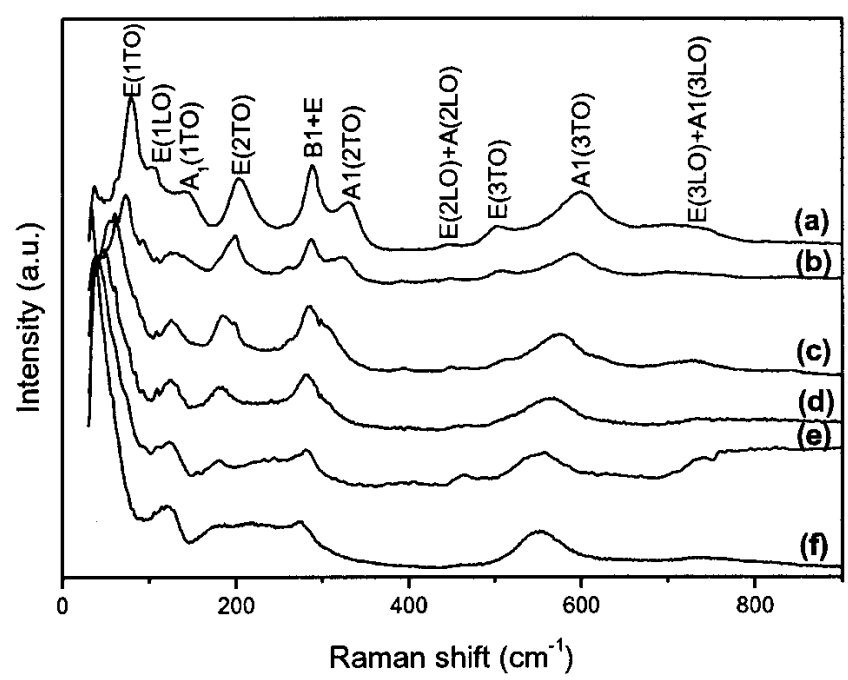

FIG. 1. Raman spectra of $\mathrm{Pb}_{1-x} \mathrm{Sr}_{x} \mathrm{TiO}_{3}$ thin films at room temperature with different compositions: (a) undoped $\mathrm{PbTiO}_{3}$ thin-film reference; (b) $x=0.10$; (c) $x=0.20$; (d) $x=0.30$; (e) $x=0.40$; (f) $x=0.50$. 
All the Raman modes are assigned according to the results of Foster et al. ${ }^{18,19}$ Raman peak frequencies are found to be extremely sensitive to $\mathrm{Sr}$ content in these samples, as shown in Fig. 2. In particular, as it is know, the lowest wave number A1(1TO) and E(1TO) phonons (considered as the "soft" mode) originate from $\mathrm{Pb}$ ions vibrating against $\mathrm{TiO}_{6}$ octahedra. The $\mathrm{Sr}$ substitution in $\mathrm{PbTiO}_{3}$ lattice affects the ionic bond between $\mathrm{Pb}$ and oxygen. As a result, the E(1TO) mode in PST thin films

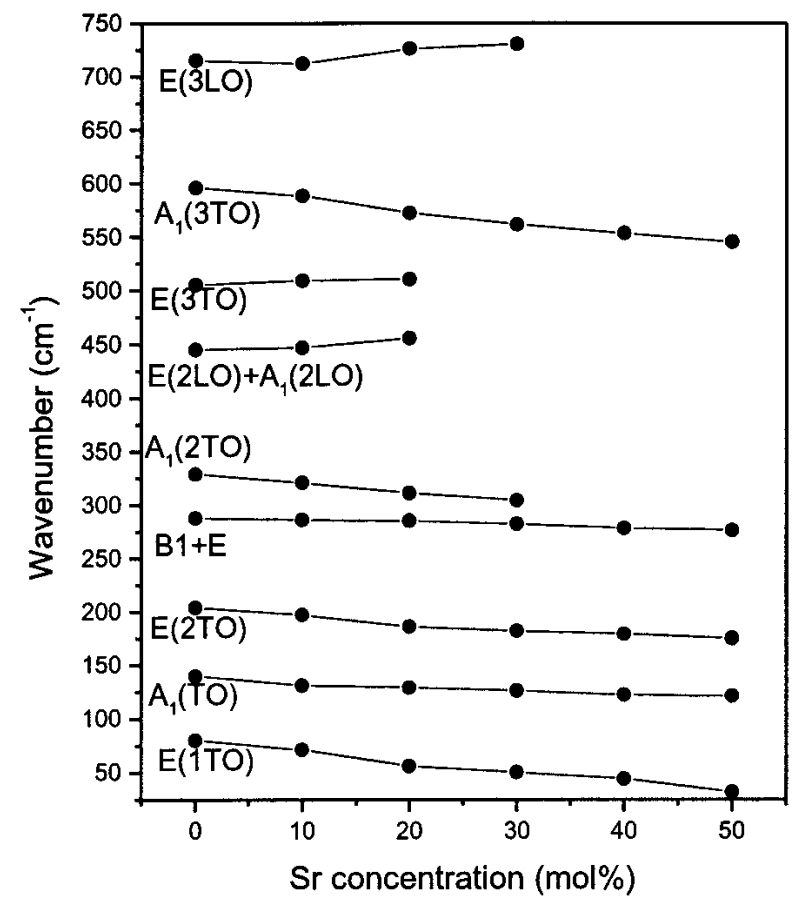

FIG. 2. Dependence of the Raman shift with the $\mathrm{Sr}$ concentration in $\mathrm{Pb}_{1-x} \mathrm{Sr}_{x} \mathrm{TiO}_{3}$ thin films.

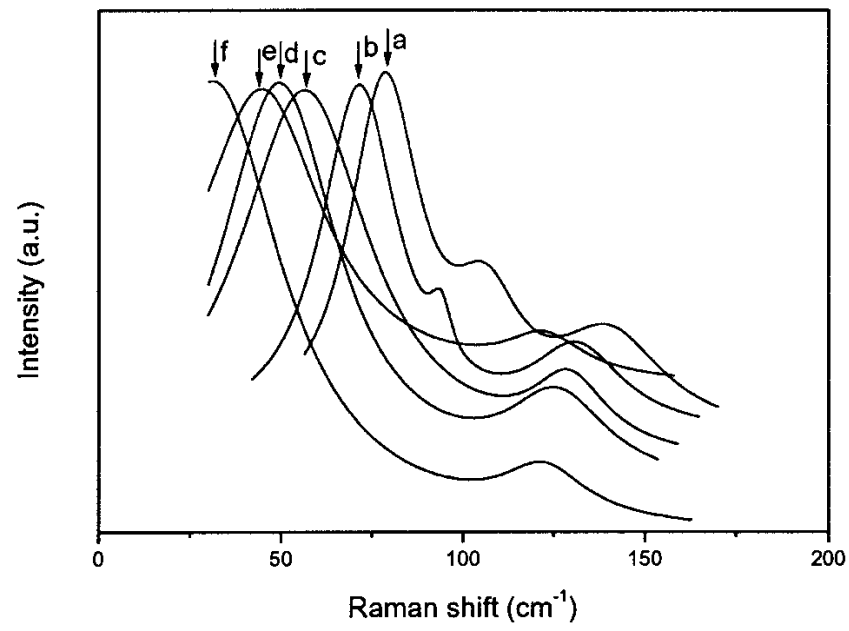

FIG. 3. Low-frequency region of the Raman spectra for the different Sr concentrations: (a) undoped $\mathrm{PbTiO}_{3}$ thin-film reference; (b) $x=$ 0.10 ; (c) $x=0.20$; (d) $x=0.30$; (e) $x=0.40$; (f) $x=0.50$. The arrows indicate the $\mathrm{E}(1 \mathrm{TO})$ soft mode. is shifted toward a lower wave number with respect to pure $\mathrm{PbTiO}_{3}$ thin film and its linewidth increases with increasing Sr content, showing a damped behavior, as can be seen in Fig. 3. This broadening can be attributed to the local disorder induced by the Sr doping, associated with the fluctuation concentration of $\mathrm{Sr}$ and/or distortion in lattice parameters, related to the differences of ionic radii between $\mathrm{Pb}$ and $\mathrm{Sr}$ ions. When the $\mathrm{Sr}$ content approaches $50 \%$, the $\mathrm{E}(1 \mathrm{TO})$ mode frequency tends to zero, indicating the tetragonal to cubic phase transition. Furthermore, for $x=0.50$, while the data from XRD analysis indicate that the crystal structure appears as pseudocubic, Raman scattering revealed the presence of a tetragonal distortion. This apparent contradiction can be explained by the fact that Raman scattering probes short-range structural order, while XRD probes longrange order.

Figure 4 shows the squared wave number of the $\mathrm{E}(1 \mathrm{TO})$ soft mode as a function of $\mathrm{Sr}$ content in the $\mathrm{PbTiO}_{3}$ lattice. According to the quadratic equation ${ }^{20}$

$$
\omega_{\mathrm{E}(1 \mathrm{TO})}^{2}(x)=\omega_{\mathrm{E}(1 \mathrm{TO})}^{2}(0)\left[1-x / x_{0}\right],
$$

the squared wave number of the soft mode tends to zero at $x_{0} \approx 0.58$. According to Fig. 4 , the phase transition from tetragonal to cubic should occur at $x_{0} \approx 0.58$. This value is very close to the tetragonal to cubic transition reported in PST (0.57) ceramics at room temperature, ${ }^{21}$ showing that the behaviors of thin films and bulk samples are similar.

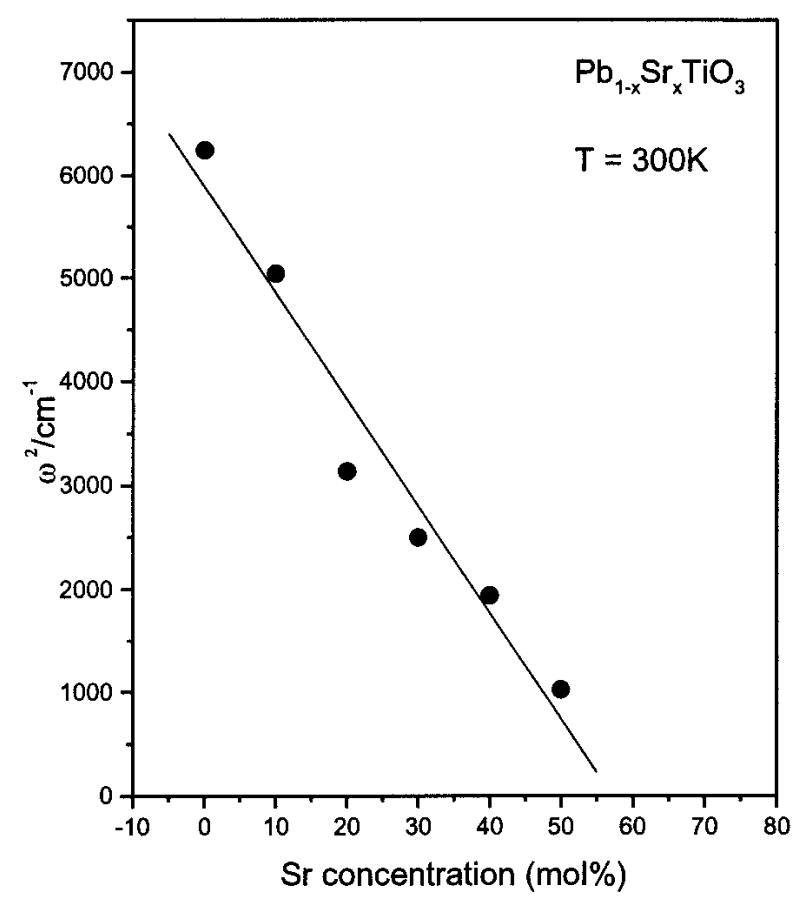

FIG. 4. Strontium concentration dependence of the squared E(1TO) mode wave number in $\mathrm{Pb}_{1-x} \mathrm{Sr}_{x} \mathrm{TiO}_{3}$ thin films. 
The infrared spectra in the oxygen-metal stretching regime between 400 and $1200 \mathrm{~cm}^{-1}$ of the PST thin films are compared in Fig. 5. The infrared spectra of pure $\mathrm{PbTiO}_{3}$ and $\mathrm{SrTiO}_{3}$ thin films are shown, for comparison. In their elementary cell of five atoms, thus there are $(3 n-3)=12$ optic modes at long wavelength. Only the optical modes can be infrared active. The three triply degenerate $T_{1 \mathrm{u}}$ modes are IR active, and so, the modes transform into $3 \mathrm{~A}_{1}+3 \mathrm{E}$ irreducible representations. ${ }^{22,23}$ Depending on the direction of propagation of the mode with respect to its polarization, the modes split into longitudinal optical (LO) and transversal optical (TO) components. The principal bands observed for pure $\mathrm{PbTiO}_{3}$ (PST0), located in the regions of 686 and $765 \mathrm{~cm}^{-1}$, correspond to the irreducible representations $\mathrm{A}_{1}(3 \mathrm{TO})$ and $\mathrm{E}(3 \mathrm{LO})$, respectively, and may be assigned to the Ti-O bond stretching vibration. ${ }^{24,25}$ The band at $886 \mathrm{~cm}^{-1}$, corresponding to the irreducible representations $\mathrm{A}_{1}(3 \mathrm{LO})$, may be attributable to the $\mathrm{Pb}-\mathrm{O}$ stretching absorbance. ${ }^{25}$ In addition, for pure $\mathrm{PbTiO}_{3}$ the IR-active modes at around 438 and $511 \mathrm{~cm}^{-1}$ are assigned to the $\mathrm{Ti}-\mathrm{O}_{3}$ torsion and to the Ti-O stretch, respectively.

We can easily recognize a series of changes of the spectra with increasing Sr content. In the spectra taken from PST thin films of different $\mathrm{Sr}$ values, the band at around $886 \mathrm{~cm}^{-1}$ is observed to decrease monotonically in its intensity and red shifts with increasing Sr value.

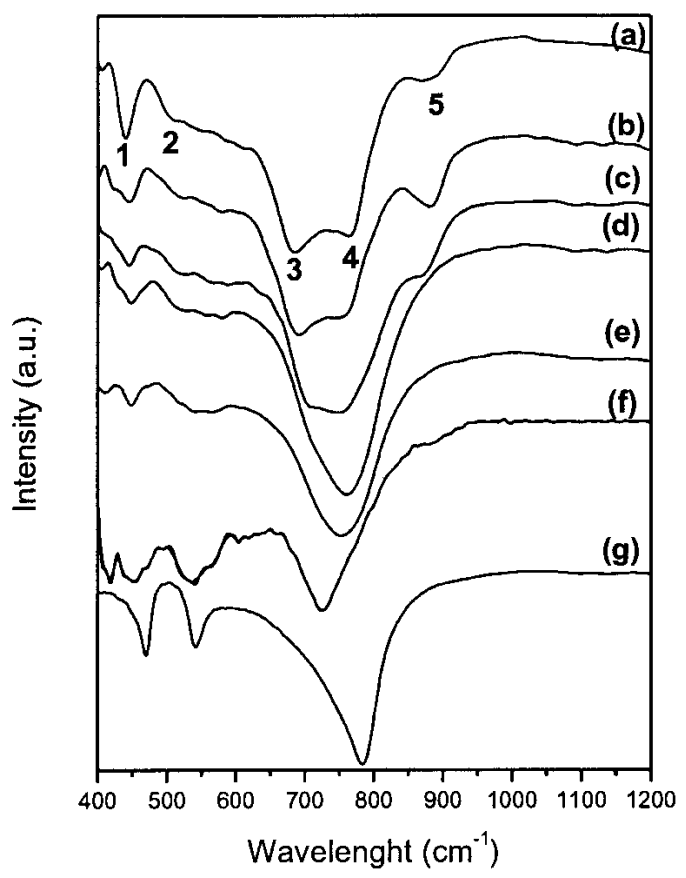

FIG. 5. IR specular reflectance spectra of $\mathrm{Pb}_{1-x} \mathrm{Sr}_{x} \mathrm{TiO}_{3}$ thin films with different $x$ values: (a) undoped $\mathrm{PbTiO}_{3}$ thin film reference; (b) $x=0.10$; (c) $x=0.20$; (d) $x=0.30$; (e) $x=0.40$; (f) $x=0.50$; (g) $x=1.0$. The numbers $1-5$ mark the possibility of phonon modes of the films.
This disappearance is obviously due to the contribution of the new $\mathrm{Sr}-\mathrm{O}$ vibrations absorbance arising from the $\mathrm{Sr}$ enrichment. Another effect is on the Ti-O bonding vibration, resulting from the augment of $\mathrm{Sr}$ content in the PST thin films, with the shift of the bands 686 and $765 \mathrm{~cm}^{-1}$, merging into a single peak which characterizes the lattice deformation. In addition, the appearance of the bands around 534 and $565 \mathrm{~cm}^{-1}$ that are assigned to the Ti-O stretch associated with the highest frequency TO mode shows the beginning of a structural transition, where these changes can be correlated with the distortion of the $\mathrm{TiO}_{6}$ octahedra which occurs as the Sr content raises. Therefore, the IR active mode at 686 and $765 \mathrm{~cm}^{-1}$ for pure $\mathrm{PbTiO}_{3}$, assigned to the Ti-O stretching, shifts for the mode corresponding to pure $\mathrm{SrTiO}_{3}$ to $777 \mathrm{~cm}^{-1}$. However, from $x=0.40$ to $x=0.50$, short peaks appear at 534 and $565 \mathrm{~cm}^{-1}$ assigned to the Ti-O stretch and the $441-\mathrm{cm}^{-1}$ mode for $\mathrm{PbTiO}_{3}$ assigned to the $\mathrm{Ti}-\mathrm{O}_{3}$ torsion [peak 1, Fig. 5(a)] shifts to the corresponding mode for $\mathrm{SrTiO}_{3}$ at $470 \mathrm{~cm}^{-1}$ associated with the LO mode. They should be related to higher Sr contents. With $\mathrm{Sr}$ concentration increasing, the structure of pure $\mathrm{PbTiO}_{3}$ thin film at room temperature loses the symmetry of tetragonal characteristics and follows a phase transition from tetragonal to cubic structure. On the other hand, the characteristics of pure $\mathrm{SrTiO}_{3}$ thin film appear gradually, and the properties of pure $\mathrm{PbTiO}_{3}$ and those of $\mathrm{SrTiO}_{3}$ thin films compete with each other. Therefore, the peaks close to 886,686 , and $765 \mathrm{~cm}^{-1}$ representing the tetragonal structure of pure $\mathrm{PbTiO}_{3}$ disappear and the peaks representing the $\mathrm{SrTiO}_{3}$ gradually appeared. ${ }^{26}$ Notice that these results are in agreement with the results presented by the micro-Raman and $\mathrm{XRD}$, in which the structural change occurs at a composition of about $\mathrm{Sr}=0.50$.

\section{CONCLUSION}

Polycrystalline single-phase perovskite $\mathrm{Pb}_{x} \mathrm{Sr}_{1-x} \mathrm{TiO}_{3}$ thin films with various $\mathrm{Sr}$ concentrations were obtained by a soft chemical process, the so-called polymeric precursor method, at an annealing temperature $600{ }^{\circ} \mathrm{C}$. They were characterized by micro-Raman spectroscopy and infrared specular spectroscopy. A gradual change from tetragonal to cubic structure, as the $\mathrm{Sr}$ concentration increases, was revealed by the evolution of the Raman spectra, mainly by the softening of the E(1TO). This implies a decrease of the Curie temperature in PST thin films as $\mathrm{Sr}$ concentration increases. The phase transition from the tetragonal to cubic phase was found to occur at $x_{0} \approx 0.58$, obtained from the extrapolation to the zero frequency of the E(1TO) soft mode dependence with the $\mathrm{Sr}$ content. The IR specular measurements at oblique incidence evidenced the optical vibrational modes of the PST thin films with perovskite structure. We found that 
the increasing tetragonal distortion of the $\mathrm{TiO}_{6}$ octahedra with increasing $\mathrm{Sr}$ concentration induces the appearance of the new perovskite bands in the spectrum characteristics of the cubic structure as the smaller $\mathrm{Sr}$ ion interacts more strongly with anions and thereby distorts the $\mathrm{TiO}_{6}$ octahedra, so as to give the resultant upward shift of the infrared mode in question. Finally, the use of both techniques, IR and Raman spectroscopy, was shown to be very efficient to provide comprehensive information on the vibrational structure of the thin ferroelectric films, which have attracted great attention due to their potential application in a variety of devices such as DRAM or NVFRAM memories.

\section{ACKNOWLEDGMENTS}

The authors gratefully acknowledge the financial support of the Brazilian financing agencies Fundação de Amparo à Pesquisa do Estudo de São Paulo (FAPESP), Conselho Nacional de Desenvolvimento Científico e Tecnológico (CNPq)/Programa de Apoio a Núcleos de Excelěncia (PRONEX), and Coordenacão de Aperfeiçoamento de Pessoal de Nível Superior (CAPES).

\section{REFERENCES}

1. L. Preda, L. Courselle, B. Despax, J. Bandet, and A. Ianculescu, Thin Solid Films 389, 43 (2001).

2. Q. Zou, S. Nourbaskhsh, and J. Kim, Mater. Lett. 40, 240 (1999).

3. F.M. Pontes, E. Longo, E.R. Leite, and J.A. Varela, Thin Solid Films 386, 91 (2001).

4. C.H. Lin, S.W. Lee, H. Chen, and T.B. Wu, Appl. Phys. Lett. 75, 2485 (1999).

5. C.H. Wang and D.J. Choi, J. Am. Ceram. Soc. 84, 207 (2001).

6. T. Iijima, G. He, and H. Funakubo, Integr. Ferroelectr. 36, 255 (2001).
7. A.A. Bosak, S.V. Samoilenkov, O.Y. Gorbenko, I.E. Graboy, A.N. Botev, A.R. Kaul, and H.W. Zandbergen, Chem. Mater. 13, 981 (2001)

8. S.Y. Chu and C.Z. Chen, Sens. Actuators, A 89, 210 (2001).

9. P. Venkateswarlu, S.S.N. Bharadwaja, and S.B. Krupanidhi, Thin Solid Films 389, 84 (2001).

10. H. Li, X. Tang, Q. Li, Y. Liu, Z. Tang, Z.Y. Zhang, and D. Mo, Solid State Commun. 114, 347 (2000).

11. M.L. Calzada, R. Sirera, J. Ricote, and L. Pardo, J. Mater. Chem. 8, 111 (1998).

12. C.C.M. Wang, Y.T. Huang, Y.C. Chen, M.S. Lee, and M.C. Kao, Jpn. J. Appl. Phys. 39, 3579 (2000).

13. G. Shen and P.Y. Du, J. Inorg. Mater. 17, 117 (2002).

14. H.J. Chung, S.J. Chung, J.H. Kim, and S.I. Woo, Thin Solid Films 394, 213 (2001).

15. D.H. Kang, J.H. Kim, J.H. Park, and K.H. Yoon, Mater. Res. Bull. 36, 265 (2001).

16. F.M. Pontes, E.B. Araújo, E.R. Leite, J.A. Eiras, E. Longo, J.A. Varela, and M.A. Pereira-da-Silva, J. Mater. Res. 15, 1176 (2000).

17. F.M. Pontes, D.S.L. Pontes, E.R. Leite, E. Longo, E.M.S. Santos, S. Mergulhão, A. Chiquito, P.S. Pizani, F. Lanciotti, Jr., T.M. Boschi, and J.A. Varela, J. Appl. Phys. 91, 6650 (2002).

18. C.M. Foster, Z. Li, M. Grimsditch, S.K. Chan, and D.J. Lam, Phys. Rev. B 48, 10160 (1993).

19. S.M. Cho and H.M. Jang, Appl. Phys. Lett. 76, 3014 (2000).

20. P.S. Dobal, S.B. Majumder, S. Bhaskar, and R.S. Katiyar, J. Raman Spectrosc. 30, 567 (1999).

21. J. Meng, G. Zou, Y. Ma, X. Wang, and M. Zhao, J. Phys.: Condens. Matter. 6, 6549 (1994).

22. G. Burns and B.A. Scott, Phys. Rev. Lett. 25, 1191 (1970).

23. V. Sivasubramanian, V.R.K. Murthy, B. Viswanathan, and M. Sieskind, J. Phys.: Condens. Matter. 8, 2447 (1996).

24. D.M. Adams, Metal-Ligand and Related Vibration (Edward Arnold, London, U.K., 1967).

25. H.Y. Chen, J. Lin, K.L. Tan, and Z.C. Feng, Thin Solid Films 289, 59 (1996).

26. W. Wu, K.H. Wong, and C.L. Choy, Thin Solid Films 360, 103 (2000). 